\title{
Stakeholder participation in agricultural research projects: a conceptual framework for reflection and decision-making
}

\author{
Andreas Neef • Dieter Neubert
}

Accepted: 17 February 2010/Published online: 21 May 2010

(C) The Author(s) 2010. This article is published with open access at Springerlink.com

\begin{abstract}
Recent discourse in the field of participatory agricultural research has focused on how to blend various forms and intensities of stakeholder participation with quality agricultural science, moving beyond the simple "farmer-first" ideology of the 1980s and early 1990s. Yet, most existing frameworks of participation in agricultural research still adhere to a linear typology of participatory research with an inherent claim of "the more participation, the better." In this article, we propose a new framework that looks at participatory research elements along different dimensions and attributes and thus takes into account the diversity and dynamics of agricultural research projects. The framework provides a basis for agricultural researchers engaged in participatory processes with local stakeholders to decide for which issues and in which phases certain participatory elements could be used in a specific research context. Rather than aiming at maximizing the adoption of participatory methods, it can thus become a tool for optimizing the use of participatory approaches in agricultural research. We conclude that this framework can be a starting point for a more thoughtful integration of participatory elements in agricultural research projects that does justice to the multidimensional and dynamic nature of stakeholder participation in varying contexts.
\end{abstract}

\footnotetext{
A. Neef $(\square)$

Faculty of Agriculture, Kyushu University, 6-10-1, Hakozaki, Higashi-ku, Fukuoka 812-8581, Japan

e-mail: aneef@agr.kyushu-u.ac.jp

D. Neubert

Department of Development Sociology, University of Bayreuth, 95440 Bayreuth, Germany
}

Keywords Agricultural research · Participatory approaches - Framework - Typologies . Scientists $\cdot$ Stakeholders

\section{Introduction}

More than 25 years after Chambers' seminal work "Rural development: Putting the last first" (Chambers 1983), the popularity of participatory approaches in rural development and agricultural research shows no sign of abating. Yet, the usefulness of participatory approaches in agricultural research has been discussed more controversially than their justification in rural development. In the late 1990s the agricultural science community was divided between the promoters of participatory research approaches and the proponents of conventional, formal research under controlled conditions. The advocates of participatory agricultural research praised the potential of the new approach for enhancing sustainable agriculture and natural resource management through incorporating local stakeholders' priorities, knowledge, and innovative capacities into the agricultural science domain (e.g., Pretty 1995) and sometimes even presented participatory research as a panacea for problems of food security and rural poverty (e.g., Chambers 1997). Critics claimed that evidence presented from participatory research projects remained isolated "islands of success" (El-Swaify et al. 1999, p. 37), mainly due to their presumably limited potential of scaling up, epistemological differences between local and scientific knowledge domains, and the social distance between farmers and agricultural scientists (Bentley 1994). There were also voices warning against a "tyranny" of participation (Cooke and Kothari 2001; for an overview of the recent critical discourse on participation, see e.g., Neubert 
2000; Neef 2003). But even among the promoters of participatory research approaches there were dissenting views and diverging schools of thought. The objectives of participatory (agricultural) research varied between political action and empowerment of the poor and marginalized (Freire 1973; Fals-Borda and Rahman 1991) at the one end of the continuum, and more functional approaches centered on involving farmers in the process of technology development and natural resource management at the other end (Werner 1993; Farrington 1998; for an overview see Selener 1997).

Notwithstanding the polarized debate on the value of participation in the 1990s, participatory approaches in international and national research centers have encountered both successes and failures (Bentley 1994; Scoones and Thompson 1994; Lilja et al. 2001; Probst 2002; Johnson et al. 2004; Lilja and Dixon 2008; van Asten et al. 2009). Since the turn of the millennium it has become evident that the claim of "the more participation, the better" articulated by the forebears of participatory rural appraisal (PRA) and participatory technology development (PTD) in the 1980s and early 1990s would need to be replaced by a more grounded discussion of the specific potential and shortcomings of participatory and conventional methods in a particular research setting. Even the most fervent proponents of participatory approaches have come to realize that participatory research should not be presented as a counter-concept to conventional research (Rocheleau 2003; Lilja and Bellon 2008). In this more mature debate on the potential and limits of participatory approaches to agricultural research positions are emerging that call for "uniting science and participation" (Pound et al. 2003), stress the need for a "compromised participation" (Buhler et al. 2002), emphasize the "comparative advantages of farmers and scientists" in generating knowledge and innovations (Hoffmann et al. 2007) and propose innovative ways to combine "local and global science" (Sillitoe 2007). As Rocheleau (2003, p. 169) puts it, "researchers are not asking if participatory methods should be used, but rather when and how, and which type of method, in combination with which traditional research tools". In a similar vein, Rhoades and Nazarea (2006, p. 337) suggest "what local communities demand is not necessarily a choice between 'participation' and 'formal research' but a new, mature relation with outside agencies and individuals."

These more conciliatory positions-stripped of the simple "farmer-first" ideologies of the past that tended to put participatory research in opposition to conventional research - are also reflected in a proliferation of approaches that combine various forms of stakeholder participation with cutting-edge scientific research. Examples are approaches like participatory plant breeding (PPB) where the newest advances in molecular biology can be combined with farmers' priority setting, evaluation, and adaptation (Weltzien et al. 2000; Christinck et al. 2005) or participatory land use modeling where innovative multi-agent system (MAS) computer models and their various scenarios are developed, validated, and refined through roleplaying games and other interactive methods (Bousquet et al. 2005; Neef et al. 2006; Becu et al. 2008).

Given the recent diversification of participatory approaches and their creative combination with highquality agricultural science, the common typologies of participatory approaches-suggesting different degrees of participation along a single scale-may no longer prove adequate for agricultural scientists to reflect on whether and in which phases they want to, can, and should incorporate participatory elements into their research projects. In an effort to address such questions in this paper, we propose a framework for reflection and decision-making with regard to participation in agricultural research projects that takes into account the increasing diversity and multidimensional character of participatory research towards sustainable agriculture, food security, and natural resource management. Following this introduction, we discuss the most recent typologies of participatory agricultural research with respect to their strengths and shortcomings. We then present the participation framework with its different dimensions and attributes and discuss the potential applications of the framework drawing primarily on our experience of applying it in a long-term interdisciplinary research program in Thailand and Vietnam. We conclude the article with some final remarks.

\section{Participatory agricultural research: a critical review of typologies}

Many analysts and practitioners of participatory research hold that there are different levels and forms of participation in research that can be structured by specific typologies. Most of these research typologies have their roots in an early classification of different degrees of citizen participation developed by Arnstein (1969). Her "participation ladder" recognizes categories ranging from manipulation (classified as non-participation), to consultation (described as a kind of tokenism), to citizen control (considered as the highest degree of citizen participation). Pretty (1995) has developed a similar typology with a strong focus on development programs and projects. His "participation scale" spans from manipulative and passive participation to interactive participation and self-mobilization. From the diversity of typologies developed for participatory (agricultural) research we choose the most recently published examples from Ashby (1996), Lambrou (2001), and Probst 
et al. (2000) since these largely draw on earlier typologies and represent the current state-of-the-art in this field.

In focusing on participatory technology development (PTD), Ashby (1996, p. 17; based on Biggs 1989) constructed a participative hierarchy of five types of participation in agricultural research: (1) nominal (farmers' land and labor are used), (2) consultative (farmers' opinions are sought), (3) action-oriented (farmers are involved in implementing parts of the research); (4) decision-making (farmers take part in decision-making processes); and (5) collegial participation (researchers strengthen farmers' own research). In the context of the CGIAR Systemwide Program on Participatory Research and Gender Analysis (SWPPGRA), Lambrou (2001) developed a typology of seven "grades" of participation, (1) positivist theoretical research (the least inclusive type of approaches), (2) passive information sharing (farmers are informed of the processes and outcomes of the research), (3) consultative stage (farmers are consulted and their needs may be included in the research design), (4) on-farm testing (researchers continue to dominate the research process, but farmers' expertise is recognized), (5) evaluation (farmers are involved in assessing the process and results of the research), (6) collaborative planning (scientists join hands with farmers in defining problems and in designing the research process), and (7) partnership (scientists and farmers engage in a long-term mutual learning and research process).

Both typologies have in common a view of participation as a linear continuum reaching from projects with a low level of participation to projects with a high degree of participation, implying "that it is possible, desirable, and necessary to move across this continuum to the most intense form of participation, a kind of participation 'nirvana'" (Gujit and Shah 1998, p. 10). Yet, increasing empirical evidence suggests that participation can take various forms and dimensions and that conventional, formal research approaches might also show elements of participation, which challenges the widespread view of participatory approaches as a new paradigm that can be categorically opposed to conventional research (Lilja and Bellon 2008; Neef 2008).

Rather than typifying agricultural research along a scale from low to high levels of stakeholder participation, Probst et al. (2000) determined key variables to describe and differentiate various research approaches: epistemological assumptions, research objectives, types of participation, the role of external and local actors' involvement, procedures/ process, and research methods. Through the combination of these factors they identify four approaches, namely (1) transfer of technology (formal research without substantial farmers' participation), (2) supply-on-demand (formal research where farmers have control over own or donated research funds), (3) farmers first (where farmers participate in the generation, testing, and evaluation of technology), and (4) participatory learning and action research (innovation is considered to be the outcome of a mutual learning process amongst a multiplicity of actors and networks). This focus on approaches highlights the different research strategies and underlying philosophies and helps to sharpen the differences between the approaches, which brings more conceptual clarity into the discussion. Probst et al. (2000) also consider the fact that farmers may influence research in different ways, either through intensive participation or control over research funds and priority setting (supply-ondemand).

Yet, similar to the shortcomings of the linear typologies developed by Ashby (1996) and Lambrou (2001), the categorization into "prototypes" does not necessarily reflect the diversity and dynamics of agricultural research projects. Projects can change over time, from transfer-oftechnology types without any participation to more demand-driven research with a higher degree of stakeholder involvement. Research projects of the "participatory learning and action" type might involve farmers during the whole process of technology generation, while the dissemination of the technology by local extension workers may follow a classical "transfer-of-technology" approach. Research projects may also have certain features that would classify them as "farmers first," whereas other features would correspond more to the "supply-on-demand" type.

We experienced the shortcomings of the existing typologies in the context of the Thai-Vietnamese-German collaborative research program "Sustainable Land Use and Rural Development in Mountainous Regions of Southeast Asia" (the so-called Uplands Program). The Uplands Program was instigated by the University of Hohenheim, Stuttgart, Germany, in collaboration with four Thai universities and four Vietnamese universities and research organizations in July 2000. The primary aim of this program is to provide the scientific basis for a better management of natural resources and the improvement of rural livelihoods in mountainous regions of northern Thailand and northern Vietnam. In its recently completed third phase (July 2006-June 2009), the program comprised a total of 15 subprojects, covering such diverse subdisciplines and specializations as soil science, agronomy, ecology, animal husbandry, economics, and rural sociology. From its conception in the year 2000, a particular objective of the program has been to ensure that participatory approaches are taken up as a cross-cutting issue in all subprojects. One subproject-headed by the authors over several yearswas assigned the role of an "umbrella project" with the dual task of (1) supporting other members of the program to apply participatory approaches in their respective 
subprojects and (2) assessing the advantages and shortcomings of combining participatory approaches with conventional agricultural and environmental research. The systematic evaluation of the potential and challenges of participatory research as applied in various disciplines, in different phases of the research program and in the specific socio-cultural contexts of Thailand, Vietnam, and Germany was regarded by the reviewers as one of the most innovative features of the Uplands Program.

Yet, this view was not equally shared by all members of our research program. One fellow scientist branded participatory research as "populist," while some others held that this kind of "soft science" approach was not very compatible with rigorous, high-quality academic research (Neef et al. 2008). Several natural scientists in our program suggested that participatory research was "something that should be done by sociologists." Some agricultural economists, on their part, believed they were already employing participatory methods when they interviewed farmers or traders with a standardized questionnaire. Among the German junior researchers, mostly Ph.D. students, only a very small minority had gained practical experience in using participatory research methods before joining the program, while more than half of the Thai and Vietnamese junior researchers already had applied participatory survey methods in their own research, although some of them saw the major value of participatory methods in their potential to "generate quick results."

Against the background of the differences of experience with participatory research approaches and the various meanings attributed to them by our fellow researchers, we believed that a common "participation typology" could help to support a more informed debate on the use of participatory methods in the various subprojects. Yet, it quickly turned out that the existing typologies and frameworks of Ashby (1996), Lambrou (2001), and Probst et al. (2000) were not fine-grained enough to depict the substantial variation of stakeholder participation among the various components of our program, ranging from subprojects that involved farmers and other local stakeholders in all stages of the research process to those where participatory elements were integrated only as "add-on activities" into otherwise conventional research (Neef 2008). The normative connotation of these typologies also risked putting off some of our colleagues who regarded participatory research with a great deal of skepticism.

\section{Towards a new framework for reflection and decision- making in participatory agricultural research}

In a first attempt to move beyond the linear typologies of Ashby (1996) and Lambrou (2001), and taking into account the fact that research projects cannot always be easily categorized into "prototypical" approaches, the second author of this article developed a "participation profile" taking into account the multidimensional scale of participation (cf. Neubert 2005). By looking at individual participatory elements in the research process, this profile intended to facilitate the evaluation of participation by using several attributes such as type of research, type of innovation, qualification, and skills acquired by farmers, and researcher-farmer interaction. Its purpose was to allow the formulation of specifically suited indicators of participation that could lead to a more differentiated reflection on participation in agricultural research. Initial tests applying this framework showed, however, that the participatory profile-involving more than 60 different indicators and elements of participation-appeared too complex for a comprehensive support of decision-making with regard to integrating participatory elements in a research project. On the other hand, other factors that can be crucial elements in participatory research, such as researchers' attitudes towards and experiences of participation, were still missing from the participation profile.

Given the shortcomings of the participation profile, we developed a new participation framework that pays particular attention to the characteristics of researchers and local stakeholders and to their various forms of interaction and is thus an adequate response to the recent diversification of participatory research approaches and the increasing understanding within the agricultural science community that participatory approaches and conventional research can be creatively and effectively combined (Pound et al. 2003; Lilja and Bellon 2008). We also have changed the focus from a normative assessment tool towards an instrument for reflection and decision-making with regard to stakeholder participation in agricultural research. The participation framework that we propose tries to take into account the complexity and dynamics of participatory agricultural research processes and the diversity of stakeholder involvement in different research contexts and research phases. Hence, we regard stakeholder participation in agricultural research as a multi-dimensional process whose various participatory elements should be considered more explicitly in planning, implementation and evaluation. The six dimensions that we suggest are (I) project type, (II) research approach, (III) researchers' characteristics, (IV) interaction between researchers and (other) stakeholders, (V) stakeholders' characteristics, and (VI) stakeholders' benefits (Fig. 1).

The order of the dimensions follows the sequence of planning and implementation of a research project: it starts with the overall research questions and the approach, looks at the actors involved and their interaction, and concludes with the (possible) impact. Each of the six dimensions 


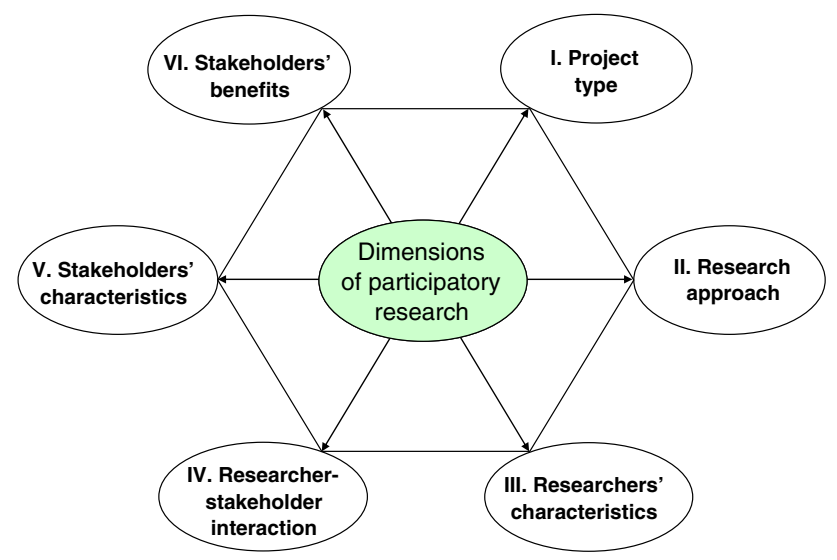

Fig. 1 Six dimensions of participatory research

comprises five attributes. The attributes characterizing the various dimensions of participation are listed in Table 1 and are described in detail below. These six dimensions and the related attributes are intended to cover the main parameters needed to describe the participatory elements employed in a given project in a systematic way.

Dimension I: project type: what is the benchmark of participation in a given project?

Before deciding on which elements of stakeholder participation may be needed in a specific research project, agricultural scientists-ideally in consultation with representatives of the local stakeholders-need to reflect on what type of research they are conducting, which objectives they pursue, whom they address with their research, and in which institutional and socio-political context they conduct the project.

\section{I.a. Type of research}

Empirical studies show that participatory methods are primarily applied in applied and adaptive stages of agricultural research, i.e., where knowledge is geared towards action (e.g., Cornwall and Jewkes 1995; Weltzien et al. 2000; Johnson et al. 2004; Lilja and Dixon 2008; van Asten et al. 2009). Basic research-i.e., experimental or theoretical research aimed at acquiring knowledge for understanding of certain phenomena without any particular application of the research in view-appears to have less potential for adopting a participatory approach. This does not imply that basic research has to be non-participatory by definition, but the degree of stakeholder participation would be generally lower than in more applied research projects, where investigations are primarily undertaken to serve a specific practical purpose (Selener 1997; Sumberg et al. 2003).

\section{I.b. Research objectives}

Whether the objective of a research project is (a) to analyze how pesticides move in the soil, (b) to identify the comparative advantages of different crop varieties, or (c) to develop a locally adapted pig breeding scheme would strongly influence the potential for involving stakeholders in the research process. The research objective of a project may be derived primarily from theoretical scientific questions with little or no relation to real-world problems or, at the other end of the continuum, it may exclusively follow stakeholders' priorities. Research with a major focus on contested concepts, such as "sustainable agriculture", may call for striking a balance between the objectives and interests of scientists, farmers, and other local stakeholders.

\section{I.c. Potential users and beneficiaries}

The potential users and beneficiaries addressed by the research project would also have a bearing on the participatory potential. There has been much debate on who are the "relevant stakeholders" or "clients" of agricultural research. For the generation of technical innovations, the primary clients would be farmers and extension workers. However, we opt for a wider definition of agricultural research that includes research on the institutional context of agriculture, such as credit, land tenure, agricultural policies and marketing, and research aimed at improving the management of natural resources (cf. Pound et al. 2003). This wider definition has implications for the range of stakeholders (e.g., policy-makers, traders, environmentalists) that need to be considered in participatory research approaches. Beneficiaries of agricultural research may also include consumers interested in high-quality food or safe drinking water.

\section{I.d. Institutional context of the research project}

Another attribute which is crucial for the participatory potential of a research project is whether it was designed and carried out in an institutional context that is responsive to the involvement of farmers' perspectives in research. If the research project is designed in a university or research institution that is less responsive to the existing problems of smallholder agriculture, it is unlikely that researchers would have the freedom to adopt participatory approaches and to respond to farmers' needs and priorities when carrying out the research. The same applies to participatory research projects that are carried out in countries or regions with a long history of supply-driven agricultural research and where the flow of information and technology is linear from researchers via extension agents to farmers (Biggs 1990; Neef 2005; Hellin et al. 2008). 
Table 1 Dimensions and their related attributes in the participation framework

\begin{tabular}{|c|c|}
\hline Dimension & Attribute \\
\hline I. Project type & $\begin{array}{l}\text { a) Type of research } \\
\text { b) Research objectives } \\
\text { c) Potential users and beneficiaries } \\
\text { d) Institutional context of the research } \\
\text { project } \\
\text { e) Risks involved in the project }\end{array}$ \\
\hline II. Project approach & $\begin{array}{l}\text { a) Research methodology } \\
\text { b) Research epistemology } \\
\text { c) Research plan } \\
\text { d) Research process } \\
\text { e) Research methods for accessing local } \\
\text { knowledge }\end{array}$ \\
\hline $\begin{array}{l}\text { III. Researchers' } \\
\text { characteristics }\end{array}$ & $\begin{array}{l}\text { a) Previous experiences with } \\
\text { participation } \\
\text { b) Attitudes towards participation } \\
\text { c) Attitudes towards local stakeholders } \\
\text { d) Accountability towards the potential } \\
\text { users } \\
\text { e) Commitment to the problem-solving } \\
\text { cycle }\end{array}$ \\
\hline $\begin{array}{l}\text { IV. Researcher- } \\
\text { stakeholder interaction }\end{array}$ & $\begin{array}{l}\text { a) Involvement of stakeholders in the } \\
\text { research process } \\
\text { b) Control of research and centers of } \\
\text { decision-making } \\
\text { c) Contribution to the generation of } \\
\text { knowledge } \\
\text { d) Type, frequency, and intensity of } \\
\text { interaction } \\
\text { e) Investment of resources and payment }\end{array}$ \\
\hline $\begin{array}{l}\text { V. Stakeholders' } \\
\text { characteristics }\end{array}$ & $\begin{array}{l}\text { a) Local stakeholders' experiences with } \\
\text { previous projects } \\
\text { b) Local stakeholders' perception of the } \\
\text { research project } \\
\text { c) Local stakeholders' perception of the } \\
\text { researchers } \\
\text { d) Time availability of local } \\
\text { stakeholders } \\
\text { e) Local stakeholders' scope for action }\end{array}$ \\
\hline VI. Stakeholders' benefits & $\begin{array}{l}\text { a) Innovations, improved practices } \\
\text { b) Creation of knowledge and awareness } \\
\text { c) Improvement of skills } \\
\text { d) Empowerment and social capital } \\
\text { e) Improvement of livelihoods }\end{array}$ \\
\hline
\end{tabular}

\section{I.e. Risks involved in the project}

Research projects may involve risks, such as the project's failure to find relevant solutions to the problems identified. The time and resources invested might not pay in terms of innovations or other outcomes generated by the project.
Projects may also carry negative side effects, for example uncontrolled spread of diseases or of transgenic plants and animals. In cases where research involves high risks, it might therefore be advisable not to involve a great number of farmers in the experiments, but to start with on-station research and controlled experiments first or to work with a few, relatively wealthy farmers who are better able to cope with the risks or who can be compensated for possible crop damage and income losses. Buhler et al. (2002), on the other hand, argue that a high risk of project failure calls for an early involvement of all relevant stakeholders in the research process.

Dimension II: research approach: methodology, epistemology, and research planning

The second dimension of participation is described by the research approach of a project. In many cases there may be typical combinations of project type (dimension I) and research approach (dimension II) but the one does not necessarily determine the other, and the combinations between the two may differ considerably from one research project to another.

\section{II.a. Research methodology}

The methodology of a project can follow a mono-disciplinary, reductionist approach, or a more system-oriented and transdisciplinary, holistic one. Scholars theorizing on conventional versus participatory research hold that the particular strength of participatory approaches lies in addressing complexity and heterogeneity in a holistic way (e.g., Buhler et al. 2002; McDougall and Braun 2003; Sumberg et al. 2003). Reductionist approaches isolating the cause-effect link by creating ceteris paribus conditions will likely have greater difficulties in applying participatory elements than system-oriented holistic approaches that are open to a wide range of perspectives and interpretations.

\section{II.b. Research epistemology}

The attribute research epistemology pinpoints the differences between research projects as regards adherence to a scientific paradigm (positivist vs. constructivist). One end of the scale is marked by a purely positivist world viewassuming that reality exists independently from the observer-i.e., a "hard science" approach where results do not depend on a given context and are of general validity. The other end is marked by a constructivist world view where reality is seen as constructed by the observer, research results acquire validity only in a given context, and therefore multiple perspectives and their individual validity are accepted. We do not, however, assume certain 
disciplines to be a priori more receptive to participatory approaches than others. Nevertheless, each discipline tends to adhere to certain epistemological assumptions that pose different challenges for embracing participatory research approaches. Thus, a purely positivist approach may be less conducive to applying participatory elements than a constructivist approach that is open to integrating local perspectives and indigenous knowledge without subjugating them completely to scientific explanations of reality (cf. Probst 2002).

\section{II.c. Research plan}

Conventional scientists tend to work out relatively rigid research plans that cannot be easily modified during the research process (cf. McDougall and Braun 2003). Such rigid planning may impede local stakeholders from influencing methods and experiments and to negotiate certain aspects of the research plan with the researchers. An open and flexible plan, on the other hand, can be more receptive to stakeholders' priorities, experiences, and perspectives, and provides space for negotiation of methods, experiments, and adaptation to new conditions. Yet, such openness and flexibility is often at odds with funding organizations that require a detailed work plan and time schedule as an integral part of the application for research funding. In such cases, scientists engaged in participatory research may need to find a balance between the requirements of funding agencies for structured planning and the need to continually adapt the research plan to changing priorities of local stakeholders.

\section{II.d. Research process}

While the research plan focuses on the practical organization of research, the research process addresses the logic of research, i.e., the basic assumption as to how research shall be conducted. In precisely formulated research projects, the research process is generally linear and formalized and its inputs and outputs are clearly defined; changing realities and problems cannot easily be taken into account (Cornwall and Jewkes 1995). At the opposite end of the scale, the research process may be seen as a continuous cycle of learning, reflection, and action, requiring regular feedback from actors and an occasional review of the relevance of research objectives and methods (Selener 1997; McDougall and Braun 2003).

\section{II.e. Research methods for accessing local knowledge}

This attribute intends to capture the differences between projects in integrating local knowledge into the process of knowledge generation. Some scientists may regard local or indigenous knowledge as less relevant for the research process or even as antagonistic to scientific knowledge on the grounds of their presumed methodological and epistemological differences and the contextuality and social embeddedness of local knowledge (Ellen and Harris 2000; for a wider discussion of this debate see Kloppenburg 1991; Agrawal 1995). Yet, an increasing number of scientists see local knowledge as a crucial component in the generation of scientific knowledge, and methods of accessing local knowledge are part and parcel of their research approach (e.g., Pound et al. 2003; Neef et al. 2006; Rhoades and Nazarea 2006; Schuler et al. 2006; Cleveland and Soleri 2007). Methods used to tap local knowledge may include various forms of individual and group interviews, participatory rapid appraisal (PRA) tools, and participant observation. Yet, researchers need to keep in mind that knowledge of farmers and other local stakeholders is often tacit and difficult to articulate, describe, and validate (Hoffmann et al. 2007). There is also evidence for the limitations of farmers' local knowledge, even when addressing localized problems (e.g., Price 2001). Rather than romanticizing local stakeholders' knowledge, local knowledge should be as critically examined as scientific knowledge that goes through a rigorous selection process by peer-reviews and constant revision by other scholars (cf. Neef 2005).

Dimension III: researchers' characteristics: differing experiences and attitudes

The first two dimensions, "project type" and "research approach," describe the formal characteristics of the research project. The third dimension moves the focus to the researchers themselves, who certainly have a major influence on the implementation of any given project. The importance attached to participation and in particular the interpretation of participation as a concept, is based on researchers' characteristics, such as experiences, views, attitudes, norms, and values (Rocheleau 2003; Lilja and Bellon 2008). Proponents of participatory research emphasize that "the question of attitudes, behavior, and values is fundamental to the successful growth of participatory approaches in all fields" (Paul, 2003, p. 139; quoted by Chambers 2005, p. 156).

\section{III.a. Previous experiences with participation}

The conventional academic training of agricultural scientists with its strong emphasis on so-called "hard science" approaches makes it hard for them to relinquish some control of the research process to local stakeholders and embrace their active input into knowledge generation (cf. 
Cornwall and Jewkes 1995; Chambers 2005). It is therefore not easy to find university graduates with a strong theoretical background in participatory research, notwithstanding practical experiences in this field. Yet, knowledge of specific methods and tools as well as experience in the practice of participation is needed to use the approach in a well-planned, self-reflective way, adapted to the specific project. As Rhoades and Nazarea (2006, p. 336) state participatory research "can be a set of effective methods in the hands of seasoned fieldworkers but can be chaotic and sometimes useless under the direction of poorly trained personnel." While there may be some exceptional cases where researchers show "natural talent" in working with local stakeholders, lack of knowledge, congeniality, and experience usually impedes the thoughtful use of a participatory approach.

\section{III.b. Researchers' attitudes towards participation}

The researchers' attitudes towards participation are another key factor in enabling a successful participatory process, although this aspect has remained largely unaddressed by scholarly research (cf. Chambers 2005). While some researchers may see participation as the guiding paradigm for agricultural research, many scientists tend to regard participatory approaches as non-scientific, impressionistic, and unreliable and therefore irrelevant for formal agricultural research (Cornwall and Jewkes 1995). Another widespread view is that participatory research entails high costs that may not always be outweighed by the benefits. There are also a growing number of agricultural scientists who hold that the scope and depth of participation may vary depending on research topic and research phase (McDougall and Braun 2003; Rocheleau 2003).

\section{III.c. Researchers' attitudes towards local stakeholders}

Researchers' attitudes towards local stakeholders can depend on a variety of factors, such as educational and cultural background, or prejudices against certain ethnic groups. Researchers may not be interested in local stakeholders' perspectives and even treat them as backward and inferior. "It is a commonplace that professionals, whether agriculturalists or not, often behave in a superior manner with farmers [...]" (Chambers 2005, p. 159). Other scientists may show great empathy for local stakeholders' perspectives and problems, see them as equal partners in research, and recognize their comparative advantages in dealing with various aspects of the research process. In the course of a research project, researchers' attitudes may change through training, regular contacts with stakeholders, and self-reflection.
III.d. Researchers' accountability towards the potential users

This attribute considers the fact that the perspective and priorities of those to whom the researchers feel accountable will influence their decisions and actions in the research process (Buhler et al. 2002). Researchers may stress only their accountability vis-à-vis project leaders, supervisors or the scientific community, including reviewers. This "upward accountability" is likely to impede an interactive engagement with local stakeholders. At the other end of the scale, researchers may think that they are only accountable to the local stakeholders as the potential users of the research results. Yet, an exclusive emphasis on "downward accountability," i.e., towards the clients of agricultural research, may prevent agricultural scientists from advancing in their academic career as the scientific community tends to favor authors of peer-reviewed journal articles based on replicable and generalizable data and research results.

\section{III.e. Researchers' commitment to the problem-solving cycle}

This attribute addresses the question to what extent are researchers responsible for all the steps within the problemsolving cycle. Opponents to a wider commitment of researchers state that research should be dedicated to the production of public goods, implying a widespread sharing of research results. This view of scientists' mandate has increasingly raised ethical concerns among different groups of society. Supporters of an extended responsibility argue that researchers have a moral commitment to local communities they are working with (e.g., van de Fliert and Braun 2002). However, whether or not researchers must also be actively involved in or even support the implementation of solutions is discussed controversially (e.g., Nagel et al. 2005).

Dimension IV: interaction between researchers and local stakeholders: who contributes to knowledge generation and who controls the research process?

Participatory agricultural research "can be defined as a systematic dialogue between farmers and scientists to solve problems related to agriculture, and ultimately to increase the impact of agricultural research," as Hellin et al. (2008, p. 81) put it. In a wider sense, this fourth dimension analyzes the interface between researchers and local stakeholders, i.e., farmers and other local groups and individuals who are directly or indirectly affected by the research. Interaction between researchers and stakeholders is an important part of the participatory practice of a project, but 
may take various forms in different types of participatory research projects.

\section{IV.a. Involvement of stakeholders in the research process}

In the 1980s and early 1990s, participatory agricultural research was often equated with farmer-driven research (e.g., Chambers 1983). With the increased focus on "sustainable agriculture," where ecological, economic and social factors need to balanced, it has been acknowledged that a larger spectrum of actors-e.g., farmers, extension workers, consumers, environmental NGOs-may be relevant in the research process. Today, we tend to define "participation" in agricultural research as the involvement of all individuals and groups who are directly and indirectly affected by the research activities and its outcomes (Neef et al. 2006). Dealing with a large number of local stakeholders, however, poses particular challenges to participatory research(ers), especially if the interests of the various stakeholders differ significantly or are even conflicting (Ashby 2003). Whether participatory approaches have to be selective in these specific circumstances or whether the researcher can act as a mediator between conflicting interests depends on the local context and the type of the research project.

\section{IV.b. Control of research and centers of decision-making}

The question of control of the research process and of the centers of decision-making must be distinguished from the issue of pure stakeholder involvement; it touches the essence of power relations between researchers and the local stakeholders (Biggs 1989; Chambers 1997; Ashby 2003; McDougall and Braun 2003). Even in cases where formal involvement of local stakeholders is substantial, researchers may still control the research process and be at the center of decision-making. Local stakeholders may or may not be informed about the decisions or they may be consulted before decisions are taken. At the other end of the continuum, farmers and other local stakeholders control the design of the research and the process of implementation, and they carry out their own surveys or experiments. One example is the formation of local agricultural research committees or CIALs (Comité de Investigación Agrícola Local), first developed in Latin America (Ashby et al. 2000; Probst 2002). Yet, purely farmer-controlled research may not be desirable in every research context, particularly when the interests of other actors, e.g., consumers, are also at stake.

\section{IV.c. Contribution to the generation of knowledge}

It is increasingly acknowledged that farmers and researchers have different comparative advantages in generating knowledge (e.g., Hoffmann et al. 2007). In a research project in New Zealand, for example, Maori farmers were insisting that their own customary knowledge-acquired through long-term experience and handed down via elders-should be merged with scientists' technical knowledge, rather than being supplemented by it (Bruges and Smith 2008). Other stakeholders-such as extension workers and local authorities-also may contribute to the generation of knowledge and innovations. Researchers may help local stakeholders with the development, monitoring and evaluation of their own technical experiments and surveys. A typical example is the farmer field school (FFS) approach where knowledge is primarily created by farmers' and extension workers' own observations and mutual exchange (e.g., van de Fliert et al. 2007).

\section{IV.d. Type, frequency, and intensity of interaction}

The type, frequency, and intensity of interaction between scientists and local stakeholders can be a decisive factor for the success of a participatory research project. In some cases, researchers meet local stakeholders only when they visit on-farm experimental sites or conduct PRA exercises. The "one-shot character" of many short-term projects carrying the label "participatory" has been repeatedly criticized (e.g., Neubert et al. 2008). Oftentimes meetings between researchers and local stakeholders in participatory research are confined to discussing logistic and technical aspects of the research. In some projects, researchers and local stakeholders meet frequently in formal meetings to discuss the research process, evaluate outcomes, and plan further steps together. Yet, practitioners need to keep in mind that the depth of a participatory approach does not necessarily increase with the number of meetings. Too many interactions can easily lead to "participation fatigue" among stakeholders (e.g., Kanji and Greenwood 2001; Neef 2005). It is also important to provide feedback on research findings to farmers and other local stakeholders in a format they can easily understand (van Asten et al. 2009).

\section{IV.e. Investment of resources and payment}

This attribute points to the division of material inputs between stakeholders and researchers. Researchers may provide all inputs, rent the experimental plots, and pay local stakeholders for their labor contribution in experiments or surveys. In the opposite, but relatively rare case, farmers and other stakeholders pay researchers for their help in identifying solutions and contribute all the research inputs, such as plots, animals, and labor. In most cases, stakeholders and researchers will both provide a reasonable share of the material inputs, which may also be determined by the specific nature of the project. Compensation for 
stakeholders involved in participatory processes needs to be carefully considered, as it may run counter to the principle that stakeholders should participate voluntarily in the research, rather than being motivated by financial incentives (cf. van Asten et al. 2009).

Dimension V: stakeholders' characteristics: agricultural research(ers) in the eyes of the local people

The fifth dimension of participation, the characteristics of the local stakeholders, is widely neglected in the discussion of participatory approaches. It is often believed that local stakeholders quasi "automatically" participate if certain conditions are met on the part of the research project, the researchers, and their methodological approach. However, this does not reflect local stakeholders' reality. Whether local stakeholders participate in a research project depends to a great extent on their own characteristics, their expectations from the project and their opportunity costs of time (Cornwall and Jewkes 1995; McDougall and Braun 2003). These may differ among individuals or particular livelihood situations and may be influenced by the political, social, economic, and cultural environment.

\section{V.a. Local stakeholders' experiences with previous projects}

This attribute highlights the fact that, in many cases, local stakeholders already have several experiences with development or research projects. From the stakeholders' perspective, research and development projects may not be easily distinguished. Both research and development projects may use survey methods for data gathering and organizing experimental trials, and they may both use more or less participatory approaches. Drawing on their experience in Ecuador, Rhoades and Nazarea (2006, p. 338) describe a situation where local people had become tired of "enthusiastic outsiders who arrived with toolkits of participatory methods," just as they had become "survey-weary in earlier years." If previous projects failed to deliver, local stakeholders are likely to approach the new research project with a great deal of skepticism and reserve.

\section{V.b. Local stakeholders' perception of the research project}

Not all research projects-whether participatory, conventional or a combination of both-are perceived as relevant by local stakeholders. In some cases, local stakeholders may find the "hard data" provided by a research project more useful than the outcomes of a participatory diagram from the PRA toolbox (Heidhues et al. 2006; Rhoades and Nazarea 2006). Farmers targeted by participatory research in New Zealand reportedly got involved in the project because they expected an increased profitability of their cropping system (Bruges and Smith 2008). A case study on participatory watershed modeling in Thailand found that local stakeholders are more willing to cooperate with scientists if there is a salient problem they need to solve and if they believe that they can influence the research process, e.g., by proposing scenarios to be tested (Becu et al. 2008).

\section{V.c. Local stakeholders' perception of the researchers}

Local stakeholders observe the behavior of researchers, categorize their social position and they use this classification in their interaction with the researchers. They may perceive the researchers as ignorant outsiders, as teachers who want to instruct them, experts providing support, or as facilitators of a continuous and mutual learning process. These perceptions will always have a strong bearing on the interaction between scientists and local stakeholders (cf. Chambers 2005). Case studies from New Zealand showed that the way farmers perceived the researchers' attitudes towards them were the most critical factor in the success or failure of the research approach (Bruges and Smith 2008). Local stakeholders' perceptions are certainly not static, but can be changed through face-to-face communication and building of trust.

\section{V.d. Time availability of local stakeholders}

Most participatory research projects demand a major commitment on the part of stakeholders in terms of labor and time (Leeuwis 2004). Yet, local stakeholders' opportunity costs of time are often underestimated by scientists engaged in participatory research approaches (Cornwall and Jewkes 1995; Neef 2005). Researchers need to be aware that "time is a precious commodity not only for scientists but also for farmers" (Hoffmann et al. 2007, p. 364) and other local stakeholders. Poor stakeholders in particular may be concerned primarily with meeting their basic needs and may not have time to get involved in research activities. Other stakeholders, often those who are better off, may have sufficient time even for continuous involvement in a long-term research project. In any case, scientists involving stakeholders in their research activities must carefully assess whether a large number of stakeholders is needed to ensure inclusiveness and a successful outcome of the research or whether working with a few representatives of the major stakeholder groups will suffice (Hoffmann et al. 2007).

\section{V.e. Local stakeholders' scope for action}

Farmers and other resource managers might be fully aware that they would need to change some of their practices or the management system but they might not be in the 
position to do anything about it (Buhler et al. 2002). The scope for action points to constraints local stakeholders are facing, for instance in changing their land use patterns or adopting soil conservation practices. In an extreme situation, stakeholders may not see any scope for changing their practices or management systems due to extreme poverty, lack of access to markets or credit, unfavorable agro-ecological conditions or a repressive institutional environment. At the other end of the continuum, stakeholders might have a variety of options and are completely free in their decision-making, since they enjoy a sound base in terms of economic resources, good access to markets and rural finance, favorable agro-ecological conditions, and a highly supportive institutional environment. Participation in agricultural research may need to adapt to these different situations, and practitioners need to be well aware of the "room for maneuver" that exist among the various stakeholder groups.

Dimension VI: stakeholders' benefits: various outcomes of participatory agricultural research

The sixth dimension of the framework addresses the crucial question of expected benefits or outcomes of participatory research. Lilja and Dixon (2008, p. 6) state that "success is often not found in the agricultural technology alone, but rather in its grounding in and building of human and social capital—confidence, knowledge, networks, and capacitywhich then allow technologies to have a full effect on livelihoods."

\section{VI.a. Innovations, improved practices}

The primary focus of development-oriented agricultural research is the generation of technical and institutional innovations and improved practices (Johnson et al. 2004). Conventional research projects may provide "turnkey" solutions that can be observed on demonstration plots or on farms of experimental farmers. In these cases the stakeholders simply have the choice to adopt or reject the innovations, without the possibility to adapting the technology to their specific farming system. In highly diverse environments, e.g., in mountainous regions, the research process would need to come up with a "basket of choices" from which farmers can select the solution that fits best to their specific circumstances (cf. McDougall and Braun 2003). While a major emphasis of participatory agricultural research has been placed on technical innovations, institutional innovations-such as a rice bank or a new management scheme for an irrigation system-are often equally important for local stakeholders. Another aspect that needs to be taken into account is the speed of the innovation process. McDougall and Braun (2003, p. 43), for instance, point to evidence that participatory plant breeding projects "consistently lead to faster release and dissemination of locally accepted varieties."

\section{VI.b. Creation of knowledge and awareness}

Increased knowledge and awareness among stakeholders can be a major outcome of a research project. They are often referred to as "disembodied" effects as they are not an integral part of the technical or institutional innovation (Lilja and Dixon 2008, p. 8). These can cover a spectrum from knowledge on a specific topic or commodity to awareness of causal relationships in agro-systems to knowledge on how whole systems or value chains function. Research may also enhance stakeholders' awareness about the positive or negative effects certain practices may have on the ecological services of a watershed or on downstream residents. Finally, a participatory project may enable stakeholders to blend their local knowledge with "expert" scientific knowledge in a complementary or even synergetic way (Price 2001; Neef et al. 2006; Hoffmann et al. 2007; van Asten et al. 2009).

\section{VI.c. Improvement of skills}

Local stakeholders' skills may improve considerably through their participation in agricultural research projects. These include diagnostic and technical skills acquired, for example, through the use of a bio-insecticide or a watersaving irrigation system. Managerial or organizational skills are often learned in the context of the collective management of grazing land (Millar and Curtis 1999) or a farmer field school (FFS), for instance (e.g., Price 2001; van de Fliert et al. 2007). The involvement with the research project may also improve the experimental skills and problemsolving capacities of the stakeholders as exemplified by the creation of farmer experimenter groups in Latin America (Ashby et al. 2000).

\section{VI.d. Empowerment and social capital}

In the past, more radical proponents of participatory approaches have called for the empowerment of local stakeholder groups through the research process in a Freirean sense, following the paradigm that participation is an end in itself rather than a means to an end (cf. Pretty 1995; Lilja and Bellon 2008). Today, most practitioners of participatory agricultural research emphasize a more functional role of participation (Hellin et al. 2008), although the question of power relations in participatory approaches is still of great relevance, particularly when the research project focuses on marginalized groups, e.g., women, ethnic minority groups or the poor. Incorporating 
stakeholders in the research process often has an impact on social capital formation. For instance, the potential for collective action among participating stakeholders can be enhanced in the course of the research. Yet, the short time frame of many research projects is often not very conducive to the formation of new organizations or strengthening of existing groups (Johnson et al. 2004). Another factor to be considered under this attribute is that there may be forms of social capital pre-existing in the targeted communities that can be crucial for the success or failure of the research project, but may be difficult to influence by project staff.

\section{VI.e. Improvement of livelihoods}

The last benefit considered is the improvement of local stakeholders' livelihoods. The research project may increase resilience of local livelihoods to external shocks and enhance the capacity of local stakeholders and institutions to adapt to changing conditions. Yet, scientists engaged in participatory research towards sustainable agriculture may often face significant tradeoffs between enhancing the economic opportunities of local stakeholders and advancing wider public policy goals, such as protection of the environment (cf. Bruges and Smith 2008). Trade-offs also frequently exist between the livelihood needs of upstream resource managers and the well-being of downstream residents, for instance, when an innovation leads to the reallocation of water resources between upstream and downstream users.

Discussion: applications, potential, and shortcomings of the participation framework

In this section we discuss the potential applications of the participation framework and some of its shortcomings drawing largely on our experience of using it to implement and assess participatory research approaches in a collaborative research program in mountainous regions of Southeast Asia.

We presented the six-dimensional participation framework to the Thai, Vietnamese, and German members of the Uplands Program during a number of workshops and individual encounters. We asked project leaders and junior researchers to evaluate their own subprojects with regard to participatory potential, elements, and methods along the different dimensions and attributes of the framework. In discussing the various dimensions and attributes of the framework, project leaders and their junior researchers, i.e., Ph.D. students, did not always come to similar conclusions as to whether a particular subproject had applied certain participatory elements or should integrate more or different stakeholders in the further research process. This was mainly due to the fact that junior researchers were the ones who had conducted the field work and thus had a more intimate knowledge of the forms and degrees of local stakeholders' participation in the respective subproject. In the case of a subproject on water-saving irrigation, for instance, the project leader assessed the research projectwhich he had designed with a participatory technology development (PTD) approach in mind-as highly participatory, i.e., involving farmers in all major steps of implementation and evaluation and providing substantial direct benefits to participating farmers. The German Ph.D. student under his supervision, who had conducted the field research together with his Thai research assistants, provided a much less participatory picture in his self-assessment, particularly reflected in low ratings of his own "participatory skills" (dimension III), his scarce encounters with farmers (dimension IV), and in his doubts whether farmers would reap any benefits from this type of research (dimensions I and VI). The apparent value of applying the participation framework was that the different perceptions were made transparent and could become a subject of informed discussion. This could lead to rethinking project types and approaches, to greater reflection on the use of participatory and non-participatory methods in a given research context, and to improved planning of future phases of the project.

Another value of the framework was the convergence of previously differing levels of understanding of the concept of participatory research among the participating scientists. Prior to applying the framework, for instance, many of our Thai and Vietnamese counterparts had shown a tendency of equating participatory approaches with the use of participatory rural appraisal (PRA), an approach that has become increasingly popular with international and national development projects in the two countries. Many of them therefore were skeptical whether such "quick" methods could generate valid scientific results. The framework contributed to raising awareness of the diversity of participatory research approaches beyond the PRA toolbox and showed how participatory methods can be combined with conventional research methods without compromising the rigor of scientific approaches.

By assessing their own subproject with the help of the participation framework, some researchers also found that they had not fully exploited the participatory potential of their respective subproject in previous phases and decided to pay more attention to the inclusion of stakeholders and their knowledge domains in subsequent funding phases. Fellow soil scientists, for example, changed their exclusive focus on scientific soil mapping-which was found to lack relevance for local land use decisions-and combined scientific and local knowledge in innovative ways which even opened up new vistas towards scaling up soil 
suitability information from local to regional level (cf. Schuler et al. 2006). In a subproject on biological pest control in fruit orchards, the German field researcher decided to broaden the reductionist approach of his research-consisting of researcher-controlled on-farm experiments with a rather low degree of interaction with farmers-by adding a study on local ecological knowledge combined with feedback for farmers on the research results of the on-farm experiments and a joint analysis of the findings (cf. Neef 2008). This add-on activity helped to get a better assessment of the major pest insects from the farmers' perspective, which provided a good basis for a follow-up project in the field of integrated pest management strategies.

Applying the framework also helped members of our program to understand that there was no a priori propensity for particular disciplines to be more "participatory" than others. Food technologists, for instance, who had previously characterized themselves as rather "non-participatory" scientists, discovered a variety of participatory elements in their projects, e.g., when they involved local processors in research on minimizing waste from fruit processing. The framework was also an eye-opener for some natural scientists who learned that much of their fellow social scientists' field research shows not more participatory elements than, for instance, agronomists' controlled crop experiments. A major lesson learned from applying the framework in a comparative perspective across various subdisciplines of the agricultural sciences was that the successful integration of participatory methods in agricultural research programs depends more on the personal characteristics of researchers (dimension III) than on their disciplinary background and the research approach (dimension II).

After it had been successfully tested and applied in the Uplands Program, the framework was also employed in another large-scale multidisciplinary research program on biodiversity conservation in Africa, involving more than 450 scientists from 13 European and African countries. This program had faced the challenge of responding to young field researchers' increasing demands for more participatory approaches and impact-orientation in an otherwise predominantly academic research program. Therefore, the program's coordinators invited the first author to present the framework in two workshops bringing together some of the senior project leaders with the junior field researchers. Discussing the analytical framework in interdisciplinary groups supported the planning process towards assessing the potential of stakeholder inclusion in the second phase and, as a highly appreciated side effect, supported participants' understanding of the methods, concepts, and underlying epistemologies of other disciplines. During one of the workshops a heated debate arose when the participants discussed the framework's attribute "research epistemology" (II.b). The major question was whether certain disciplines, such as cultural anthropology and ecology, follow a more positivist or a more constructivist paradigm. While this controversy could not be resolved during the workshop, the framework had helped to stimulate such interdisciplinary debate that is a crucial element in collaborative research programs. Yet, most importantly, the framework helped to convince both natural and social scientists that participatory research approaches can broaden the methodical portfolio in biodiversity research and increase its relevance for local stakeholders.

One of the challenges in applying the participation framework is that it is rather time-consuming due to the number of dimensions and attributes considered and the resulting complexity. Hence, some of our fellow scientists simply refused to participate in interdisciplinary workshops where the framework was discussed and employed as a tool for self-reflection and assessment of participatory elements in the respective subprojects. Apparently, there is a trade-off between the potential of such a framework to cover the broadest possible range of participatory elements that may play a role in research projects and the framework's user-friendliness. Agricultural and development economists, whose respondents in formal surveys usually comprise large samples and whose research is more addressed to policy-makers as end-users rather than to farmers, generally found the participation framework less suitable for assessing their own research than other social scientists, such as anthropologists and rural sociologists, due to difficulties in reflecting on stakeholders' characteristics (dimension III) and stakeholders' benefits (dimension VI).

Notwithstanding these shortcomings, the framework proved helpful in stimulating informed debate and selfreflection on the use and usefulness of participatory research methods in particular research contexts and in various research phases. Recently, the Office for Technology Impact Assessment of the German Parliament has endorsed the framework as an effective tool for reflecting on the potential of participatory agricultural research towards solving the global food security problem. While this framework was developed primarily for the application in the field of agricultural sciences, it has already proved its potential use in environmental science projects with a focus on change, such as biodiversity conservation programs (see above). Adapted forms of the framework may also be applied in other science fields, where stakeholder participation has been increasingly discussed in recent years, such as health and educational sciences (cf. Cornwall and Jewkes 1995). Development practitioners and extension workers may also want to test the application of such a framework for planning and assessing stakeholder 
participation in rural development projects and agricultural extension programs.

\section{Conclusion}

The participation framework was developed to serve a number of objectives. It enables-with its subdivision into dimensions and attributes-a process of self-reflection, informed discussion, and decision-making with regard to the usefulness of applying participatory elements in a specific research context. It may help to identify particular strengths, opportunities, and limitations of stakeholder inclusion in a research project and can assist in monitoring and planning the evolution of research projects with regard to participatory elements over several research phases.

The framework tries to overcome the shortcomings of linear and prototypical typologies in participatory agricultural research. Rather than being a normative tool for assessing the degree of stakeholder participation in research-implicit in some of the earlier typologies and frameworks - the participation framework can provide a sound basis for reflecting on and planning the use of participatory approaches in agricultural research which has become increasingly diversified in recent years. The aim is to optimize the use of participatory approaches in a given research context, not to maximize the application of participatory methods in agricultural research in general (cf. Kanji and Greenwood 2001).

We conclude that the framework can make a contribution to informing the still controversial debate on the value and significance of participatory approaches in the agricultural sciences. For a critical and productive reflection on agricultural research involving various types of stakeholders beyond the science domain, we need a differentiated and structured discussion on the potential and limitations of participatory approaches in the specific context of a project and on how participatory elements can be successfully integrated into research practice. The participation framework may serve as a starting point for an improved methodology that offers the possibility to decide on the use of participatory approaches in a more meaningful, creative and transparent way, while doing justice to the multidimensional, dynamic nature of stakeholder participation in various research contexts.

Acknowledgments This participation framework was developed in the context of the Thai-Vietnamese-German Collaborative Research Center "Sustainable Land Use and Rural Development in Mountainous Regions of Southeast Asia" (The Uplands Program) funded by the German Research Foundation (DFG), the National Research Council of Thailand, and the Vietnamese Ministry of Science and Technology. The participation framework was a result of many discussions in the project on participatory methods applied in various subprojects in Thailand and Vietnam. Rupert Friederichsen who applied different versions of the framework helped us with his constructive criticism. We are indebted to Stephen Biggs, Robert Chambers, Harvey S. James, Jr., Franz Heidhues, Laura DeLind, Jules Pretty, and five anonymous reviewers who gave valuable comments on earlier versions of the participation framework and of this paper.

Open Access This article is distributed under the terms of the Creative Commons Attribution Noncommercial License which permits any noncommercial use, distribution, and reproduction in any medium, provided the original author(s) and source are credited.

\section{References}

Agrawal, A. 1995. Dismantling the divide between indigenous and scientific knowledge. Development and Change 26: 413-439.

Arnstein, S.R. 1969. A ladder of citizen participation. Journal of the American Institute of Planners 35(4): 216-224.

Ashby, J.A. 1996. What do we mean by participatory research in agriculture? In New frontiers in participatory research and gender analysis, Proceedings of the International Seminar on Participatory Research and Gender Analysis (PRGA), 9-14 September 1996, ed. CIAT (Centro Internacional de Agricultura Tropical), 15-22. Cali, Colombia: CIAT.

Ashby, J. 2003. Introduction: Uniting science and participation in the process of innovation-Research for development. In Managing natural resources for sustainable livelihoods: Uniting science and participation, ed. B. Pound, S. Snapp, C. McDougall, and A. Braun, 1-19. London: Earthscan.

Ashby, J., A. Braun, T. Gracia, M. Guerrero, C.A. Quirós, and J.I. Roa. 2000. Investing in farmer researchers: Experience in Latin America. Cali, Colombia: Centro Internacional de Agricultura Tropical (CIAT).

Becu, N., A. Neef, P. Schreinemachers, and C. Sangkapitux. 2008. Participatory computer simulation to support collective decisionmaking: Potential and limits of stakeholder involvement. Land Use Policy 25(4): 498-509.

Bentley, J.W. 1994. Facts, fantasies, and failures of farmer participatory research. Agriculture and Human Values 11: 140-150.

Biggs, S. 1989. Resource-poor farmer participation in research: A synthesis of experiences from nine national agricultural research systems. OFCOR comparative study paper. The Hague: International Service for National Agricultural Research (ISNAR).

Biggs, S. 1990. A multiple source of innovation model of agricultural research and technology promotion. World Development 18(11): 1481-1499.

Bousquet, F., G. Trébuil, S. Boisseau, C. Baron, P. d'Aquino, and J.C. Castella. 2005. Knowledge integration for participatory land management: The use of multi-agent simulations and a companion modelling approach. In Participatory approaches for sustainable land use in Southeast Asia, ed. A. Neef, 291-310. Bangkok: White Lotus.

Bruges, M., and W. Smith. 2008. Participatory approaches for sustainable agriculture: A contradiction in terms? Agriculture and Human Values 25: 13-23.

Buhler, W., S. Morse, E. Arthur, S. Bolton, and J. Mann. 2002. Science, agriculture, and research: A compromised participation?. London: Earthscan.

Chambers, R. 1983. Rural development: Putting the last first. New York: Longman.

Chambers, R. 1997. Whose reality counts?. London: Intermediate Technology Publications.

Chambers, R. 2005. Ideas for development. London and Sterling: Earthscan. 
Christinck, A., E. Weltzien, and V. Hoffmann (eds.). 2005. Setting breeding objectives and developing seed systems with farmers. A handbook for practical use in participatory plant breeding projects. Weikersheim: Margraf Publishers and Wageningen, The Netherlands: Center for Tropical Agriculture (CTA).

Cleveland, D.A., and D. Soleri. 2007. Farmer knowledge and scientist knowledge in sustainable agricultural development: Ontology, epistemology, and praxis. In Local science vs. global science: Approaches to indigenous knowledge in international development, ed. P. Sillitoe, 209-229. New York/Oxford: Berghahn Books.

Cooke, B., and U. Kothari (eds.). 2001. Participation: The new tyranny?. London: Zed Books.

Cornwall, A., and R. Jewkes. 1995. What is participatory research? Social Sciences and Medicine 41(12): 1667-1676.

Ellen, R., and H. Harris. 2000. Introduction. In Indigenous environmental knowledge and its transformations-Critical anthropological perspectives, ed. R. Ellen, P. Parkes, and A. Bicker, 1-34. Amsterdam: Harwood Academic Publishers.

El-Swaify, S., and D. Evans, with an international group of contributors. 1999. Sustaining the global farm: Strategic issues, principles, and approaches. 10th International Soil Conservation Organization Conference, West Lafayette, Indiana, USA.

Fals-Borda, O., and M.A. Rahman. 1991. Action and knowledge. Breaking the monopoly with participatory action research. London: Intermediate Technology Publications.

Farrington, J. 1998. Organisational role in farmer participatory research and extension: Lessons from the past decade. Natural resources perspectives No. 27. London: Overseas Development Institute (ODI).

Freire, P. 1973. Education for critical consciousness. New York: Seabury Press.

Gujit, I., and M.K. Shah. 1998. Waking up to power, conflict and process. In The myth of community: Gender issues in participatory development, ed. I. Gujit, and M.K. Shah, 1-23. London: Intermediate Technology Publications.

Heidhues, F., K. Stahr, U.-J. Nagel, D. Thomas, and A. Neef. 2006. Lessons learned and future challenges for integrated and participatory approaches to mountain research. Journal of Mountain Science 3(4): 347-354.

Hellin, J., M.R. Bellon, L. Badstue, J. Dixon, and R. La Rovere. 2008. Increasing the impacts of participatory research. Experimental Agriculture 44: 81-95.

Hoffmann, V., K. Probst, and A. Christinck. 2007. Farmers as researchers: How can collaborative advantages be created in participatory research and technology development? Agriculture and Human Values 24: 355-368.

Johnson, N., N. Lilja, J. Ashby, and J.A. Garcia. 2004. The practice of participatory research and gender analysis in natural resource management. Natural Resources Forum 28: 189-200.

Kanji, N., and L. Greenwood. 2001. Participatory approaches to research and development in IIED: Learning from experience. London: International Institute of Environment and Development (IIED).

Kloppenburg, J. 1991. Social theory and the de/reconstruction of agricultural science: Local knowledge for an alternative agriculture. Rural Sociology 56(4): 519-548.

Lambrou, Y. 2001. A typology: Participatory research and gender analysis in natural resource management research. Working document No. 15. Cali, Colombia: CGIAR Participatory Research and Gender Analysis Program, CIAT (Centro Internacional de Agricultura Tropical).

Leeuwis, C. with contributions from A. van den Ban. 2004. Communication for rural innovation: Rethinking agricultural extension. Third Edition. Oxford: Blackwell Publishing.
Lilja, N., and M. Bellon. 2008. Some common questions about participatory research: A review of the literature. Development in Practice 18(4-5): 479-488.

Lilja, N., and J. Dixon. 2008. Responding to the challenges of impact assessment of participatory research and gender analysis. Experimental Agriculture 44: 3-19.

Lilja, N., J.A. Ashby, and L. Sperling (eds.). 2001. Assessing the impact of participatory research and gender analysis. Cali, Colombia: Participatory Research and Gender Analysis Program, CIAT (Centro Internacional de Agricultura Tropical).

McDougall, C., and A. Braun. 2003. Navigating complexity, diversity, and dynamism: Reflections on research for natural resource management. In Managing natural resources for sustainable livelihoods: Uniting science and participation, ed. B. Pound, S. Snapp, C. McDougall, and A. Braun, 20-47. London: Earthscan.

Millar, J., and A. Curtis. 1999. Challenging the boundaries of local and scientific knowledge in Australia: Opportunities for social learning in managing temperate upland pastures. Agriculture and Human Values 16: 389-399.

Nagel, U., F. Heidhues, P. Horne, and A. Neef. 2005. Participatory technology development and local knowledge for sustainable land use in Southeast Asia: Lessons learned and challenges ahead. In Participatory approaches for sustainable land use in Southeast Asia, ed. A. Neef, 359-370. Bangkok: White Lotus.

Neef, A. 2003. For discussion: Participatory approaches under scrutiny-Will they have a future? Quarterly Journal of International Agriculture 42(4): 489-497.

Neef, A. 2005. Participatory approaches and local knowledge for sustainable land use-An introduction. In Participatory approaches for sustainable land use in Southeast Asia, ed. A. Neef, 3-32. Bangkok: White Lotus.

Neef, A. 2008. Integrating participatory elements in conventional research projects: Measuring the costs and benefits. Development in Practice 18(4-5): 576-589.

Neef, A., F. Heidhues, K. Stahr, and P. Sruamsiri. 2006. Participatory and integrated research in mountainous regions of Thailand and Vietnam: Approaches and lessons learned. Journal of Mountain Science 3(4): 305-324.

Neef, A., R. Friederichsen, and D. Neubert. 2008. Juggling multiple roles or falling between all stools? Insider action research in a collaborative agricultural research program in Southeast Asia. Sociologus 1(2008): 55-80.

Neubert, D. 2000. A new magic term is not enough. Participatory approaches in agricultural research. Quarterly Journal of International Agriculture 39(1): 25-50.

Neubert, D. 2005. Are promises kept? Towards a framework for the evaluation of participatory research. In Participatory approaches for sustainable land use in Southeast Asia, ed. A. Neef, 73-96. Bangkok: White Lotus.

Neubert, D., A. Neef, and R. Friederichsen. 2008. Interaktive Methoden: Erfahrungen mit der Verwendung von "Participatory Rural Appraisal" (PRA) in der Forschung. In Forschen unter Bedingungen kultureller Fremdheit, ed. G. Cappai, 95-126. Wiesbaden: Verlag für Sozialwissenschaften.

Paul, B. 2003. PRA values: How to become a true believer. In Pathways to participation: Reflection on PRA, ed. A. Cornwall, and G. Pratt, 135-139. Rugby: ITDG Publishing.

Pound, B., S. Snapp, C. McDougall, and A. Braun (eds.). 2003. Managing natural resources for sustainable livelihoods: Uniting science and participation. London: Earthscan.

Pretty, J. 1995. Participatory learning for sustainable agriculture. World Development 23(8): 1247-1263.

Price, L.L. 2001. Demystifying farmers' entomological and pest management knowledge: A methodology for assessing the 
impacts on knowledge from IPM-FFS and NES interventions. Agriculture and Human Values 18: 153-176.

Probst, K., J. Hagmann, T. Becker, and M. Fernandez. 2000. Developing a framework for participatory research approaches in risk-prone environments. Paper presented at Deutscher Tropentag, University of Hohenheim, Stuttgart, Germany. https://www.uni-hohenheim.de/atsaf/download/iaks/ probst_et_al_pr+nrm.pdf. Accessed 20 July 2006.

Probst, K. 2002. Participatory monitoring and evaluation: A promising concept in participatory research? Lessons from two case studies in Honduras. Weikersheim: Margraf Publishers.

Rhoades, R.E., and V. Nazarea. 2006. Reconciling local and global agendas in sustainable development: Participatory research with indigenous Andean communities. Journal of Mountain Science 3(4): 334-346.

Rocheleau, D. 2003. Participation in context: What's past, what's present, and what's next. In Managing natural resources for sustainable livelihoods: Uniting science and participation, ed. B. Pound, S. Snapp, C. McDougall, and A. Braun, 169-183. London: Earthscan.

Schuler, U., C. Choocharoen, P. Elstner, A. Neef, K. Stahr, M. Zarei, and L. Herrmann. 2006. Soil mapping for land-use planning in a karst area of North Thailand with due consideration of local knowledge. Journal of Plant Nutrition and Soil Science 169(3): $444-452$.

Scoones, I., and J. Thompson (eds.). 1994. Beyond farmer first: Rural people's knowledge, agricultural research, and extension practice. London: Intermediate Technology Publications.

Selener, D. 1997. Participatory action research and social change. Ithaca, New York: Cornell University.

Sillitoe, P. (ed.). 2007. Local science vs. global science: Approaches to indigenous knowledge in international development. New York and Oxford: Berghahn Books.

Sumberg, J., C. Okali, and D. Reece. 2003. Agricultural research in the face of diversity, local knowledge and the participation imperative: Theoretical considerations. Agricultural Systems 76: 739-753.

Van Asten, P.J.A., S. Kaaria, A.M. Fermont, and R.J. Delve. 2009. Challenges and lessons when using farmer knowledge in agricultural research and development projects in Africa. Experimental Agriculture 45: 1-14.
Van de Fliert, E., and A.R. Braun. 2002. Conceptualizing integrative, farmer participatory research for sustainable agriculture: From opportunities to impact. Agriculture and Human Values 19: 2538.

Van de Fliert, E., Ngo Tien Dung, O. Henriksen, and J.P.T. Dalsgaard. 2007. From collectives to collective decision-making and action: Farmer field schools in Vietnam. Journal of Agricultural Education and Extension 13(3): 245-256.

Weltzien, E., M.E. Smith, L.S. Meitzner, and L. Sperling. 2000. Technical and institutional issues in participatory plant breeding from the perspective of formal plant breeding. A global analysis of issues, results and current experience. Cali, Colombia: CGIAR Systemwide Program on Participatory Research and Gender Analysis (PRGA Program).

Werner, J. 1993. Participatory development of agricultural innovations. Procedures and methods of on-farm research. Eschborn: German Agency for Technical Cooperation (GTZ).

\section{Author Biographies}

Andreas Neef is Adjunct Professor in Knowledge and Innovation Management at the Faculty of Agriculture, Kyushu University, Fukuoka, Japan. He holds a Ph.D. degree in Agricultural Economics and Rural Sociology from the University of Hohenheim, Stuttgart, Germany. His research focuses on participatory approaches to agricultural research, innovation processes, resource tenure, and decentralization of natural resource management. From July 2000 to March 2009 he coordinated the Thai-Vietnamese-German Collaborative Research Center for Sustainable Land Use and Rural Development in Mountainous Regions of Southeast Asia in Chiang Mai, Thailand.

Dieter Neubert is Professor of Development Sociology at the University of Bayreuth, Germany. His major research and teaching emphasis is on political sociology in Africa, sociology of development policy, sociology of violent conflicts, local knowledge, and participatory research. 